
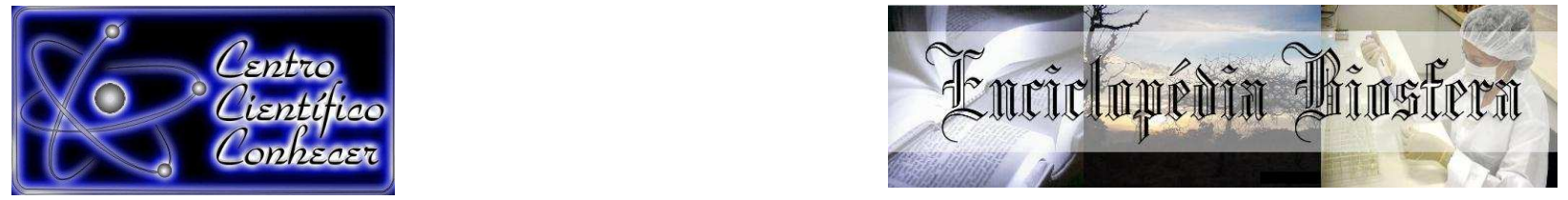

\title{
LEVANTAMENTO FLORÍSTICO E FITOSSOCIOLÓGICO DE UM FRAGMENTO DE FLORESTA OMBRÓFILA DENSA NO MORRO DOS MACACOS, PASSO DE TORRES - SC
}

Monique Bohora Schlickmann ${ }^{1}$, Tarik Cuchi², Jaqueline Beatriz Brixner Dreyer ${ }^{2}$, Jéssica Thalheimer de Aguiar², Jader Lima Pereira ${ }^{3}$

${ }^{1}$ Bióloga, mestranda do Programa de Pós-graduação em Engenharia Florestal da

Universidade do Estado de Santa Catarina, Lages - Brasil (nique_bn@hotmail.com)

2 Eng. Florestal, mestrando (a) do Programa de Pós-graduação em Engenharia Florestal da Universidade do Estado de Santa Catarina

${ }^{3}$ Professor (MSc.) do Departamento de Ciências biológicas da Universidade do Extremo Sul

Catarinense

Recebido em: 03/10/2016 - Aprovado em: 21/11/2016 - Publicado em: 05/12/2016 DOl: 10.18677/EnciBio_2016B_062

Levantamentos florísticos e fitossociológicos são de extrema importância na avaliação do comportamento de espécies presentes em um ecossistema. Assim, o objetivo deste trabalho consistiu na caracterização da comunidade arbórea de um fragmento de Floresta Ombrófila Densa. O local do estudo é conhecido como Morro dos Macacos, no estado de Santa Catarina. Todo material coletado seguiu a identificação taxonômica do sistema proposto por APG IV para angiospermas. O levantamento foi realizado pelo método de ponto de quadrante, sendo alocados cinco pontos distantes 50 metros entre si. Foram amostrados indivíduos arbóreos, vivos, com circunferência à altura do peito $(C A P) \geq 12 \mathrm{~cm}$. O levantamento registrou a ocorrência de 15 espécies distribuídas em 13 gêneros e 10 famílias. Dentre as famílias encontradas, Meliaceae apresentou a maior riqueza específica (27\%), seguida de Fabaceae e Myrtaceae (13\%). Já as espécies com maior valor de VI deste remanescente florestal foram Cupania vernalis (70\%) e Guapira opposita (60\%). A floresta do Morro dos Macacos encontra-se influenciada pela ação antrópica e em estado médio de regeneração, sendo que o maior número de espécies encontradas caracterizam-se como secundárias. Os resultados encontrados auxiliarão estudos futuros de dinâmica em remanescentes de Floresta Ombrófila Densa e também em programas de manejo, preservação ou ainda recuperação ambiental.

PALAVRAS-CHAVE: Fitossociologia. Floresta Ombrófila Densa. Florística.

\section{FLORISTIC LIFTING AND PHYTOSOCIOLOGICAL OF A FRAGMENT OF DENSE OMBROPHILOUS FOREST IN THE MORRO DOS MACACOS - PASSO DE TORRES - SC}

\begin{abstract}
Floristic and phytosociological surveys are extremely important in assessing the behavior of species in an ecosystem. The objective of this study was to characterize the arboreal community of a fragment of Ombrophilous Dense Forest. The study site is known as Morro dos Macacos, in the state of Santa Catarina. All material collected followed the taxonomic identification of the system proposed by APG IV for
\end{abstract}


angiosperms. The survey was conducted by Quadrants point methods, being allocated 5 points with a distance of 50 meters apart. Arboreal living individuals were sampled, with circumference at chest level $(C A P) \geq 12 \mathrm{~cm}$. The survey registered the presence of 15 species in 13 genders and 10 families. Among the families found, Meliaceae had the highest number of species (27\%), followed by Fabaceae and Myrtaceae (13\%). As for the species with the highest amount of $\mathrm{VI}$ of this remnant forest were Cupania vernalis (70\%) and Guapira opposita (60\%). Morro dos Macacos forest is influenced by human action and its states at an undergoing regeneration, and its largest number of species that were found are characterized as secondary. The results will help future studies of dynamics in the remaining Dense rain forest and also in management programs, conservation or environmental recovery.

KEYWORDS: Phytosociological. Dense ombrophilours forest. Floristic.

\section{INTRODUÇÃO}

A Mata Atlântica é considerada um dos maiores Biomas, pois é grandiosa em biodiversidade da Fauna e Flora, composta por cerca de 10.000 espécies de plantas, $50 \%$ delas são endêmica (SATO, 1995), é um dos ecossistemas de maior diversidade biológica do mundo (ANDRADE et al. 2014). Refere-se a um tipo de floresta tropical que tem status de patrimônio nacional garantido pela Constituição Brasileira de 1988, em seu artigo 225, e pela Lei 11.428 de 2006 (BRASIL, 2006). Esse bioma já cobriu cerca de $15 \%$ do território nacional e, a partir de ações antrópicas, foi perdendo terreno, hoje reduzido a $7 \%$ de sua configuração original, além de encontrar-se em diferentes estágios de regeneração (SOS MATA ATLÂNTICA, 2016; MMA, 2016).

Dentre as diversas formações vegetacionais do bioma Mata Atlântica tem-se a Floresta Ombrófila Densa que se distribui do Rio Grande do Norte até o Rio Grande do Sul (FRANKE et al., 2005). Este tipo de vegetação é caracterizado por seu perfil ombrotérmico, estando preso a fatores climáticos tropicais de altas temperaturas (médias de $25^{\circ} \mathrm{C}$ ) e de elevada precipi tação, bem distribuída durante o ano, o que condiciona uma situação bioecológica praticamente sem período biologicamente seco (IBGE, 2012).

Esta unidade fitogeográfica apresenta particularidades marcantes, como a grande presença de espécies arbóreas, diferentes classes de diâmetro, idade, características ecofisiológicas, taxas de crescimento e incremento distintas (OLIVEIRA et al., 2012). Ademais, cabe salientar que, conforme VIBRANS (2012) atualmente esta floresta apresenta em sua maioria remanescentes florestais em estágio secundário de regeneração.

Segundo PASETTO (2015) a conservação da biodiversidade regional é vista como um dos maiores obstáculos a serem superados atualmente, levando em consideração o elevado nível de perturbações antrópicas, aos quais estão inseridos os ecossistemas naturais. Também o rápido crescimento das populações humanas e a procedente expansão de suas atividades têm alterado as paisagens naturais não só localmente, mas em todo o globo (TABARELLI, 2012).

Deste modo, torna- se importante discutir as formas de preservação, sendo, que de fato, para continuar usufruindo dos benefícios provenientes da natureza, precisa-se envolver certas perspectivas e a utilização de métodos, que só trarão bons resultado, se obtiver grande conhecimento dos elementos pertencentes a natureza (PASETTO, 2015).

Neste contexto, a fitossociologia é considerada como uma importante ferramenta para determinar as espécies florestais mais relevantes em um 
determinado grupo florístico. ARAÚJO et al. (2015), corroboram com esta ideia, afirmando que o estudo dos parâmetros fitossociológicos, geram informações que proporcionam uma melhor compreensão do domínio das espécies e suas respectivas importâncias ecológicas no fragmento em estudo, avaliando-as por meio do comportamento, estrutura e estratos da vegetação.

Conhecer a diversidade biológica nos remanescentes florestais, quantificá-los e conseguir entender sua organização espacial, oferece um conhecimento sobre essas áreas, até então não perceptíveis (PASETTO, 2015). Porém, apesar da importância de estudos sobre o bioma Mata Atlântica e suas formações florestais, atualmente ainda pouco se sabe sobre os processos físicos, químicos e biológicos existentes nesse bioma (ANDRADE et al. 2014). Desta forma, o objetivo deste estudo foi realizar o levantamento florístico e análise dos parâmetros fitossociológicos da comunidade arbórea no Morro dos Macacos, localizado na cidade de Passo de Torres, Santa Catarina.

\section{MATERIAL E MÉTODOS}

O estudo foi realizado em um fragmento florestal de 20 hectares de extensão, na localidade do Morro dos Macacos, no município de Passo de Torres, extremo sul de Santa Catarina (Figura 1). O local corresponde as coordenadas geográficas entre $49^{\circ} 43^{\prime} 22^{\prime \prime}$ ao oeste e $29^{\circ} 14^{\prime} 66^{\prime \prime}$ ao sul.

A região está inserida segundo a classificação de KÖPPEN (1931) na tipologia climática Cfa (subtropical chuvosa), enquadrando-se no clima regional quente e temperado com a existência de pluviosidade média de $1398 \mathrm{~mm}$ ao longo do ano. A temperatura média no município é de $18,8^{\circ} \mathrm{C}$, já a média da temperatura mais alta é de $23.4^{\circ} \mathrm{C}$ nos meses de janeiro (CLIMAT E-DATA, 2016).

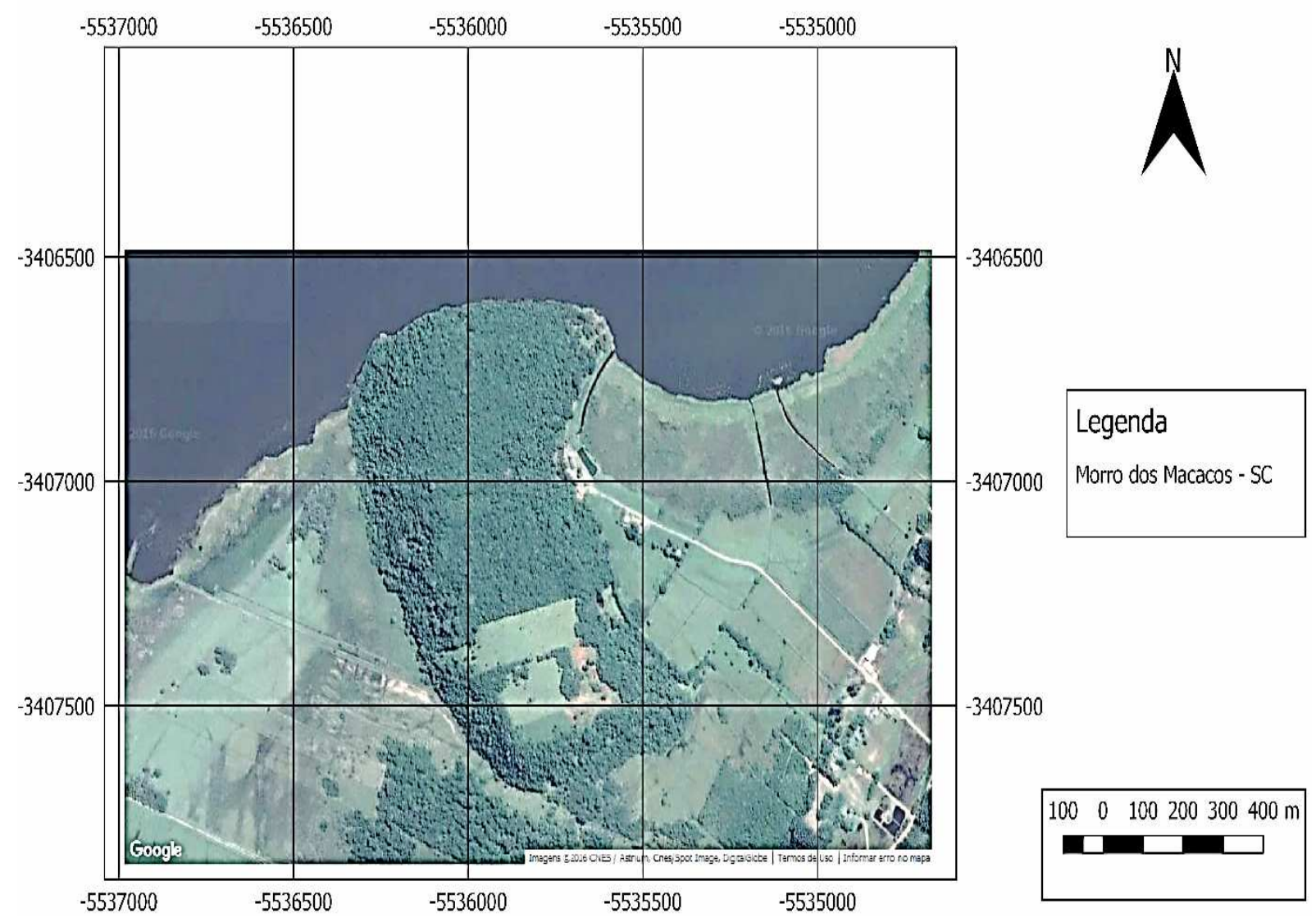

FIGURA 1. Mapa de localização do fragmento florestal do Morro dos Macacos gerado no QGIS com imagem da base de dados da API Google Earth. 
Segundo GUIMARÃES (1997), a vegetação original de Floresta Ombrófila Densa do morro era formada por grandes árvores, inclusive figueiras, mas com o passar dos anos, a floresta foi sendo substituída por monoculturas como o arroz, o fumo e o reflorestamento com espécies exóticas, principalmente o pinus e 0 eucalipto. Além desses fatores, SANTOS (2008) ressalta que a ocupação humana as margens da Lagoa próxima ao remanescente florestal, intensificou a degradação, ameaçando tanto a lagoa quanto fragilizando todo ecossistema associado.

Para o levantamento de dados foi utilizado o método de ponto de quadrante (COTTAM \&CURTIS, 1956). Este é um método que dispensa a instalação de uma área amostral, oferecendo maior rapidez em sua consecução (FREITAS, 2012), visto que se baseia em um ponto definindo um plano cartesiano de quatro quadrantes (FREITAS, 2012). Ainda segundo FREITAS (2012) a distância de um ponto a outro deve ser precisamente determinada sendo que somente um indivíduo será coletado de cada lado do quadrante.

Desta forma, os dados foram coletados em outubro de 2015 ao longo de $2 \mathrm{~km}$ próximo à trilha situada no Morro dos Macacos. Foram alocados 5 pontos amostrais, com $50 \mathrm{~m}$ de distância entre si, onde então foram amostrados os quatro indivíduos mais próximos ao ponto, sendo indivíduos arbóreos com circunferência à altura do peito (CAP) igual ou superior a $12 \mathrm{~cm}$.

O material coletado foi levado ao Herbário Pe. Raulino Reitz na Universidade do Extremo Sul Catarinense (UNESC), onde foram identificadas de forma taxonômica com o auxílio do sistema proposto por APG IV (2016) para angiospermas. Com base nos dados de campo, foram calculados os parâmetros fitossociológicos usuais: área basal, riqueza, abundância, dominância, frequência e densidade, absolutas e relativas, valores de cobertura e valores de importância.

\section{RESULTADOS E DISCUSSÃO}

A composição da flora arbórea de toda a área estudada resultou em 15 espécies, 13 gêneros e 10 famílias distintas representadas abaixo (Quadro 1). As demais famílias encontradas foram, Annonaceae, Euphorbiaceae, Malvaceae, Nyctaginaceae, Salicanaceae, Sapindaceae e Solanaceae, onde estas, apresentaram uma menor representatividade na região, ou seja, foram encontradas apenas uma espécie cada (7\% por família), conforme a figura 2.

QUADRO 1 - Lista florística das espécies Arbóreas, da floresta ombrófila densa, do Morro dos Macacos, SC.

\begin{tabular}{|c|c|c|}
\hline FAMÍLIA & ESPÉCIE & NOME POPULAR \\
\hline ANNONACEAE & Annona neosericea H.Rainer & Cortiça \\
\hline EUPHORBIACEAE & Gymnanthes concolor Spreng. & Laranjeira-do-mato \\
\hline FABACEAE & Machaerium stipitatum (DC.) Vogel & Farinha-seca \\
\hline FABACEAE & Bauhinia forficata Link & Pata-de-vaca \\
\hline MALVACEAE & Luehea divaricata Mart. \& Zucc. & Açoita-cavalo \\
\hline MELIACEAE & Trichilia claussenii C.DC. & Cafeeiro-do-mato \\
\hline MELIACEAE & Trichilia elegans A. Juss. & Pau-de-ervilha \\
\hline MELIACEAE & Trichiliapallens C. DC. & Baga-de-morcego \\
\hline MELIACEAE & Cabralea canjerana (Vell.) Mart. & Cangerana \\
\hline MYRTACEAE & Eugenia brasiliensis Lam. & Grumixama \\
\hline MYRTACEAE & Campomanesia xanthocarpa O.Berg & Guabiroba \\
\hline
\end{tabular}

ENCICLOPÉDIA BIOSFERA, Centro Científico Conhecer - Goiânia, v.13 n.24; p.664 2016 


\begin{tabular}{|c|c|c|}
\hline NYCTAGINACEAE & Guapira opposita (Vell.) Reitz & Maria-mole \\
\hline SALICACEAE & Casearia sylvestris Sw. & Chá-de-bugre \\
\hline SAPINDACEAE & Cupania vernalis Cambess & Camboatá-vermelho \\
\hline SOLANACEAE & Solanum pseudocapsicum L. & Laranjinha-de-jardim \\
\hline
\end{tabular}

Dentre as dez famílias identificadas, Meliaceae foi a que apresentou o maior número de espécies (27\%), seguida de Fabaceae e Myrtaceae (13\%), resultados similares, quanto a maior representatividade dessas famílias foram encontrados por GEORGIN et al. (2015) em um uma floresta estacional decidual.

A família Meliaceae segundo CRONQUIST (1988), abrange cerca de cinco gêneros e 120 espécies distribuídos por toda a Região Neotropical. Dessas, 16 espécies estão agrupadas em quatro gêneros que ocorrem como espécies arbóreas e nativas no Sul do Brasil, onde também se encontra a maior concentração dessa família (KLEIN, 1984).

$\mathrm{Na}$ região Sul do Brasil, espécies de Myrtaceae são relativamente muito encontradas em diversos estudos (COLONETTI et al., 2009), mostrando dessa forma a importância sociológica dessa família na mata atlântica. A família Fabaceae segundo Leitão Filho (1987) são muito comuns e no normalmente apresentam um maior número de espécies e indivíduos. Peixoto et al. (2015) estudando a restinga no município de Rio de Janeiro, encontrou a maior quantidade de espécies inseridas também nas famílias Myrtaceae e Fabaceae.

\section{Distribuição das espécies por família}

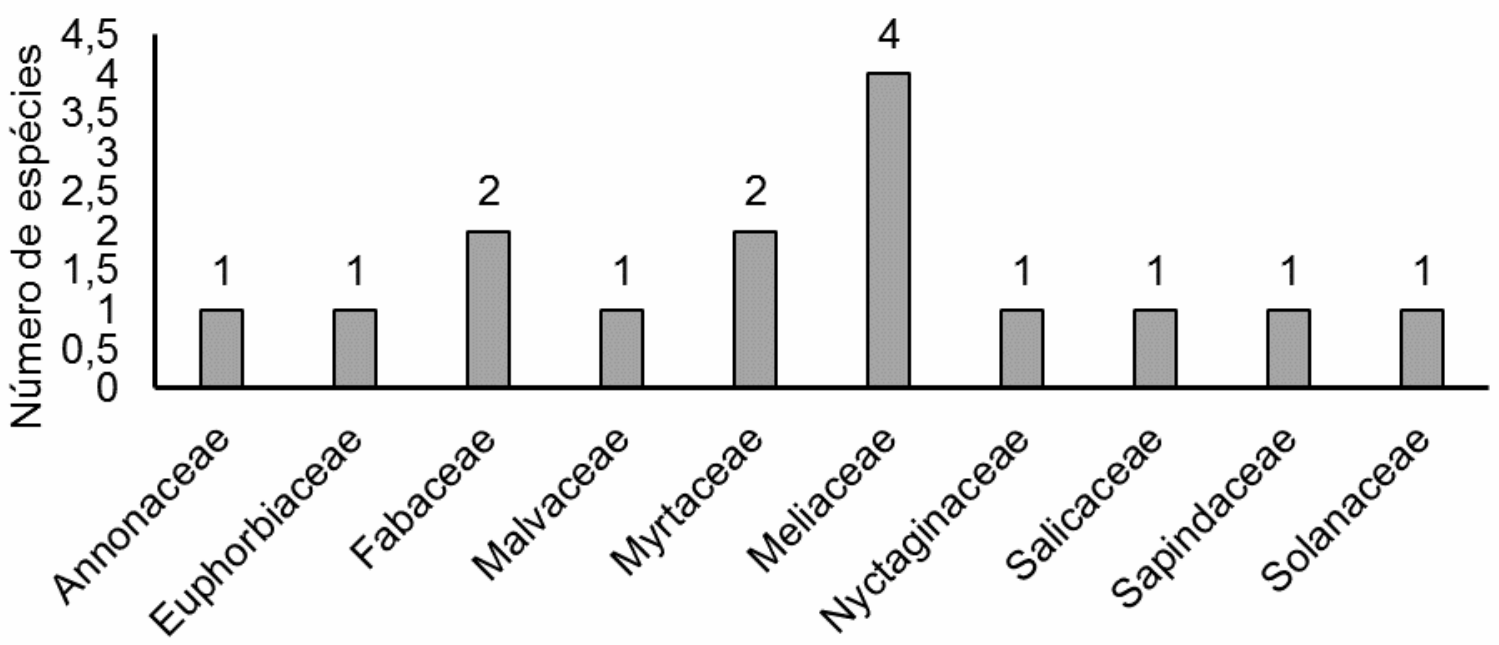

Família

FIGURA 2 - Distribuição das espécies por família levantadas na vegetação arbórea da Localidade do Morro dos Macacos - SC.

Com base nos dados coletados em campo, como PAP = perímetro do caule a altura do peito; $\mathrm{DAP}=$ Diâmetro do caule a altura do peito; Distância do ponto e Altura da vegetação Arbórea, foi possível calcular os parâmetros fitossociológicos das espécies estudadas. As espécies que apresentaram maior valor de importância foram, Guapira opposita e Cupania vernalis, presentes em quase todos os pontos de amostragem, totalizando $44,07 \%$ de todos os indivíduos amostrados (Tabela 2). 
TABELA 2 - Parâmetros fitossociológicos estimados para as espécies Arbóreas do Morro dos Macacos, Passo de Torres, SC. Abi = Área basal da espécie i $\left(\mathrm{m}^{2}\right) ; \mathbf{N i}=$ Número de indivíduos amostrados da espécie i; $\mathbf{N P i}=$ Número de Pontos com a espécie; DA = Dominância absoluta; $\mathbf{D R}=$ Dominância relativa; $\mathbf{F A}=$ Frequência absoluta; $\mathbf{F R}=$ Frequência relativa; $\mathbf{D o A}=$ Dominância Absoluta; $\mathbf{D o R}=$ Dominância relativa; $\mathbf{V C}=$ Valor de cobertura; $\mathbf{V I}=$ Valor de importância.

\begin{tabular}{|c|c|c|c|c|c|c|c|c|c|c|c|}
\hline ESPÉCIE & $\mathbf{A B i}$ & $\mathbf{N i}$ & NPi & DA & DR & FA & FR & DoA & DoR & VC & VI \\
\hline G. opposita & 0,441 & 20 & 12 & 105,5 & 25,0 & 60 & 20,3 & 10,5 & 38,0 & 63,0 & 83,3 \\
\hline C. vernalis & 0,273 & 22 & 14 & 116,1 & 27,5 & 70 & 23,7 & 6,5 & 23,5 & 51,0 & 74,7 \\
\hline T. claussenii & 0,202 & 11 & 10 & 58,0 & 13,8 & 50 & 17,0 & 4,8 & 17,4 & 31,1 & 48,1 \\
\hline T. elegans & 0,085 & 7 & 4 & 36,9 & 8,8 & 20 & 6,8 & 2,0 & 7,3 & 16,1 & 22,9 \\
\hline C. silvestres & 0,055 & 4 & 4 & 21,1 & 5,0 & 20 & 6,8 & 1,3 & 4,7 & 9,7 & 16,5 \\
\hline L. divaricata & 0,023 & 3 & 2 & 15,8 & 3,8 & 10 & 3,4 & 0,5 & 2,0 & 5,7 & 9,1 \\
\hline G. concolor & 0,008 & 2 & 2 & 10,6 & 2,5 & 10 & 3,4 & 0,2 & 0,7 & 3,2 & 6,6 \\
\hline $\begin{array}{c}\text { S. } \\
\text { pseudocapsicum }\end{array}$ & 0,007 & 2 & 2 & 10,6 & 2,5 & 10 & 3,4 & 0,2 & 0,6 & 3,1 & 6,5 \\
\hline M. stipitatum & 0,005 & 2 & 2 & 10,6 & 2,5 & 10 & 3,4 & 0,1 & 0,5 & 3,0 & 6,4 \\
\hline T. pallens & 0,003 & 2 & 2 & 10,6 & 2,5 & 10 & 3,4 & 0,1 & 0,2 & 2,7 & 6,1 \\
\hline E. brasiliensis & 0,032 & 1 & 1 & 5,3 & 1,3 & 5 & 1,7 & 0,8 & 2,7 & 4,0 & 5,7 \\
\hline B. forficata & 0,012 & 1 & 1 & 5,3 & 1,3 & 5 & 1,7 & 0,3 & 1,0 & 2,3 & 4,0 \\
\hline C. xanthocarpa & 0,009 & 1 & 1 & 5,3 & 1,3 & 5 & 1,7 & 0,2 & 0,8 & 2,1 & 3,7 \\
\hline A. neosericea & 0,006 & 1 & 1 & 5,3 & 1,3 & 5 & 1,7 & 0,1 & 0,5 & 1,8 & 3,4 \\
\hline C. canjerana & 0,001 & 1 & 1 & 5,3 & 1,3 & 5 & 1,7 & 0,0 & 0,1 & 1,4 & 3,0 \\
\hline
\end{tabular}

CALLEGARO et al. (2013) também encontraram uma grande representatividade da espécie Cupania vernalis, em seu estudo de regeneração natural em um fragmento de floresta ombrófila mista, alegando desta forma que o maior número de indivíduos encontrados desta espécie, se deva ao fato das mesmas possuírem dispersão zoocórica e também capacidade de se desenvolver sob diversas condições ambientais.

Cupania vernalis por aparecer na maioria dos pontos (14), foi a espécie que mais se destacou nos parâmetros de frequência e densidade, porém seus indivíduos apresentarem diâmetros menores. Guapira opposita foi a que apresentou maior valor de importância, KORTE et al. (2013) encontraram resultados congruentes em seu estudo realizado também no estado de Santa Catarina. Ainda segundo os autores essa espécie constituí o estrato superior das florestas, podendo medir de 4 a $12 \mathrm{~m}$.

As duas espécies em questão, $C$. vernalis e $G$. opposita são classificadas como secundárias iniciais, a classificação seguiu a proposta de GANDOLFI et al. (1995), que relacionam as espécies em pioneiras, secundárias iniciais e secundárias tardias, sendo os grupos pertinentes às três categorias de sucessão: fase inicial, média e avançada de sucessão, respectivamente (SILVA et al. 2003). Considera-se desta forma que o fragmento em questão, esteja em estágio médio de sucessão, devido à forte presença de tais espécies, (G. opposita e $C$. vernalis). Os resultados encontrados são pertinentes com o histórico de degradação do fragmento florestal.

A espécie Trichilia claussenii, comparando com as demais espécies, apresentou também um número relativamente alto de indivíduos, sendo esta ENCICLOPÉDIA BIOSFERA, Centro Científico Conhecer - Goiânia, v.13 n.24; p.666 2016 
considerada uma espécie clímax, resultados semelhantes foram encontrados por GEORGIN et al. (2015) em uma floresta estacional decidual do Alto - Uruguai, RS, mostrando também uma boa representatividade desta espécie, na área em questão. A presença desta espécie no fragmento estudado demonstra que o mesmo está se encaminhando para um estágio avançado de sucessão, sendo um resultado positivo na recuperação do fragmento.

Foi constatado em estudo sobre a fitossociologia realizado em subformações de um fragmento de Floresta Estacional Decidual por SCIPIOINI et al. (2011) no noroeste do estado do Rio Grande do Sul, a ocorrência das mesmas espécies indicadoras no primeiro nível de divisão e consideraram essas espécies como responsáveis pela identificação dos estágios secundários avançado e inicial para as respectivas espécies, Trichilia claussenii e Cupania vernalis, resultado semelhante ao encontrado nesse estudo.

SCCOTI et al. (2011) analisando um remanescente de floresta estacional semidecidual, concluíram que $T$. claussenii possui um grande potencial de perpetuação. Explicando desta forma, a grande concentração de indivíduos encontrados para esta espécie na localidade do Morro dos Macacos. Ainda segundo SILVEIRA et al. (2015), essa espécie é encontrada com certa frequência em florestas nativas na região central e na fronteira oeste do Rio Grande do Sul, sendo popularmente conhecida como catiguá na região.

Luehea divaricata e Bauhinea forficata são segundo o Instituto Ambiental do Paraná (2012), espécies secundárias e indicadas para recuperação de ecossistemas florestais degradados. Estas espécies apresentaram pequena presença na área estudada, talvez esse resultado, deva-se ao fato de ambas espécies possuírem dispersão anemocórica, e o respectivo fragmento é uma floresta de mata fechada, impossibilitando desta forma a entrada de vento e consequentemente a dispersão dessas espécies sob diferentes áreas.

Ao contrário de VENTUROLI et al. (2015), que verificaram que a comunidade florestal estudada apresentada como uma floresta autoregenerante, mas em estágio de sucessão secundária, com a presença de muitos indivíduos jovens, com diâmetros à altura do peito menores do que dez centímetros. Afirmou ainda e fato se deve às intervenções silviculturais propostas, especialmente, pela intervenção que envolveu a supressão de vegetação competidora associada ao corte de cipós.

As demais espécies foram pouco representativas no levantamento, apresentando frequências moderadamente baixas, algumas apareceram somente uma única vez durante todo o estudo, tais como, E. brasilliensis, B. forficata, $C$. xantothocarpa, $A$. neosericea e $C$. canjerana. De acordo com FRANCESCHINELLI et al. (2015), a fragmentação de hábitats ou o ataque de pragas em sementes, são fatores que afetam o sucesso reprodutivo de espécies florestais. Desta forma, como base no histórico de degradação sofrido pela área e suas redondezas, sugere-se que esse tenha sido o motivo para a baixa frequência encontrada por tais espécies no fragmento estudado. Porém a grande representatividade encontrada pela espécie clímax Trichillia claussenii, aponta que a área esteja se restaurando naturalmente.

\section{CONCLUSÃO}

O fragmento estudado na localidade de Morro dos Macacos caracteriza-se por uma pequena quantidade de espécies dominando a área, mas apresentando certa diversidade de espécies menos frequentes. A família mais característica do fragmento foi Meliaceae, seguida de Myrtaceae e Fabaceae. Já as espécies mais 
incidentes foram, Cupania vernalis e Guapira opposita, classificadas como secundárias iniciais. A presença destas espécies, bem como de Trichilia claussenii, espécie clímax, é vista como um ponto positivo para o fragmento.

\section{REFERÊNCIAS}

ARAÚJO, L. H. B.; SILVA, R. A. R.; CHAGAS, K. P. T.; NÓBREGA, C. C.; SANTANA, J. A. S. Composição florística e estrutura fitossociológica de um fragmento de Floresta Ombrófila Densa no município de Macaíba, RN. Revista Agroambiente On-line, [S.I.], v. 9, n. 4, p. 455-464, 2016. Disponível em: <http://dx.doi.org/10.18227/1982-8470ragro.v9i4.2441>. doi: 10.18227/19828470ragro.v9i4.2441

ANDRADE, A. M. D. DE; MOURA, M. A. L.; SANTOS, A. B. DOS; CARNEIRO, R. G.; SILVA JR., R. S. DA. Radiação Fotossinteticamente Ativa incidente e refletida acima e abaixo do dossel de floresta de Mata Atlântica em Coruripe, Alagoas. Revista Brasileira de Meteorologia, v. 29, n. 1, 2014. Disponível em: <http://dx.doi.org/10.1590/S0102-77862014000100007>. doi: 10.1590/S010277862014000100007

APG IV. An update of the Angiosperm Phylogeny Group classification for the orders and families of flowering plants: APG IV. Botanical Journal of the Linnean Society, v. 181, p. 1-20, 2016. Disponível em: <http://dx.doi.org/10.1111/boj.12385>. doi: 10.1111/boj.12385

BRASIL. Lei no 11.428 de 2006. Utilização e proteção da vegetação nativa do Bioma Mata Atlântica. Disponível em: <http://www.planalto.gov.br/ccivil_03/_ato20042006/ 2006/lei/l11428.htm>.

CALLEGARO, R. M.; LONGHI, S. J.; ANDRZEJEWSKI, C.; ARAUJO, M. M. Regeneração natural de espécies arbóreas em diferentes comunidades de um remanescente de floresta ombrófila mista. Ciência Rural, v. 45, n. 10, p. 1795-1801, 2015. Disponível em: <http://dx.doi.org/10.1590/0103-8478cr20131098>. doi: 10.1590/0103-8478cr20131098

CLIMATE-DATA. CLIMA: Passo de Torres, 2016. Disponível em: <http://pt.climatedata.org/location/313599/>.

COLONETTI, S.; CITADINI-ZANETTE, V.; MARTINS, R.; SANTOS, R.; ROCHA, E.; JARENKOW, J. A. Florística e estrutura fitossociológica em Floresta Ombrófila Densa Submontana na barragem do rio São Bento, Siderópolis, Estado de Santa Catarina. Acta Scientiarum Biological Sciences, v. 31, n. 4, p. 397-405, 2009. Disponível em: <http://dx.doi.org/10.4025/actascibiolsci.v31i4.3345>. doi: 10.4025/actascibiolsci.v31i4.3345.

COTTAM, G.; CURTIS, J. T. The use of distance measures in phiytosociological sampling. Ecology, v. 37, n. 3, p. 451-460, 1956. Disponível em: <http://dx.doi.org/10.2307/1930167>. doi: $10.2307 / 1930167$ 
CRONQUIST, A. The evolution and classification of flower ing plants. Lawrence, Printedby Allen Press, Inc., p. 555, 1988.

FRANCESCHINELLI, E. V.; CARMO, R. M.; SILVA-NETO, C. M.; GONÇALVES, B. B.; BERGAMINI, L. The reproductive success of Cabralea canjerana (Vell.) Mart. (Meliaceae) in Atlantic Forest fragments in Brazil. Revista de Biologia Tropical, v. 63, n. 1, p. 515-524, 2015. Disponível em: < http://www.scielo.sa.cr/scielo.php?script=sci_arttext\&pid=S0034-7744201500020001 $5>$.

FRANKE, C. R.; ROCHA, P. L. B.; KLEIN, W.; GOMES, S. L. Mata Atlântica e biodiversidade. Edufba: Salvador - BA, p. 461, 2005.

FREITAS, W. K. de. Métodos e Parâmetros para Estudo da Vegetação com Ênfase no Estrato Arbóreo. Flora, Florestas e Ambientes, v. 4, n. 19, p.520-540, 2012. Disponível em: <http://dx.doi.org/10.4322/floram.2012.054>. doi: 10.4322/floram.2012.054

GANDOLFI, S.; LEITÃO FILHO, H. F.; BEZERRA, C. L. E. Levantamento florístico e caráter sucessional das espécies arbustivo arbóreas de uma floresta mesófila semidecídua no município de Guarulhos, SP. Revista Brasileira de Biologia, v. 55, n. 4, p. 753-767, 1995. Disponível em: <http://www.lcb.esalq.usp.br/publications/articl es/1995/1995rbbv55n4p753-767.pdf>.

GEORGIN, J.; ELOY, J. B.; OLIVEIRA, G. A., DENARDIN, A. L. da R.; LAZZARI, L. Aspectos florísticos e fitossociológicos de uma floresta estacional decidual, na região do alto Uruguai - RS. Revista Eletrônica Em Gestão, Educação e Tecnologia Ambiental, v. 19, n. 2, p. 1400-1412, 2015. Disponível em: $<$ https://periodicos.ufsm.br/reget/article/view/16885/pdf>.

http://dx.doi.org/10.5902/2236117016885

GUIMARÃES, R. J. Lagoa do Sombrio: História e Degradação. Sombrio, 1997.

IBGE. Manual técnico da vegetação brasileira. Rio de Janeiro, Ed. 2, p. 271, 2012.

INSTITUTO AMBIENTAL DO PARANÁ - IAP. Projeto de recomposição de áreas degradadas e 2012 alteradas, Disponível em: <http://www.iap.pr.gov.br/modules/conteudo/conteudo.php?conteudo=1353>.

KLEIN, R. M. Meliáceas. In: R. Reitz (ed.), Flora llustrada Catarinense. R. Reitz ed. Itajaí, p. 138, 1984.

KÖPPEN, W. Climatologia. México, Fundo de Cultura Econômica, 1931.

KORTE, A; GASPER, A. L de; KRUGER, A; SEVEGNANI, L. Composição florística e estrutura das restingas em Santa Catarina. Inventário Florístico Florestal de Santa Catarina: Floresta Ombrófila Densa. Edifurb: Blumenau - SC, v. 4, 2013. 
LEITÃO FILHO, H. F. Considerações sobre a florística de florestas tropicais e subtropicais no Brasil. UNICAMP, n.35, p.41-46, abr.1987. Disponível em: <http://www.ipef.br/PUBLICACOES/SCIENTIA/nr35/cap02.pdf>.

MINISTÉRIO DO MEIO AMBIENTE - MMA. Mata Atlântica, 2016. Disponível em: $<$ http://www.mma.gov.br/biomas/mata-atlantica>.

OLIVEIRA, T. M.; ALVES, A. R.; AMARALL, G. C.; ALMEIDA, K. N. S.; SOUZA, K. B.; AGUIAR A. S.; ARAUJO E. F.; FARIAS, S. G. G. Análise da estrutura vegetacional em uma área de transição Cerrado - Caatinga no município de Bom Jesus-PI. Revista Scientia Plena, v. 8, n. 4, 2012. Disponível em: <https://www.scientiaplena.org.br/sp/ article/view/1407/673>.

PASETTO, R.; BOSA, M. M.; SANTOS, D.; DILTON, R. P. Florística e estrutura do componente arbóreo de uma floresta ombrófila densa montana em Santa Catarina, Brasil. Revista Árvore, v. 39, 2015. Disponível em: <http://dx.doi.org/10.15 90/010067622015000100005>. doi: 10.15 90/0100-67622015000100005.

PEIXOTO, J.; FAVORETO, C.; LIMA, A.; RIBEIRO, B. Levantamento florístico das mudas de restinga produzidas no horto restinga no município do Rio de Janeiro, RJ, Brasil. Revista Internacional de Ciências, 2015. Disponível em: < http://dx.doi.org/10.12957/ric.2015.18566>. doi: 10.12957/ric.2015.18566.

SANTOS, C. R. Proposta dos critérios de planejamento da gestão integrada da orla marítima dos municípios do litoral Sul de Santa Catarina. Florianópolis, p. 208, 2008. Disponível em: <http://www.nmd.ufsc.br/pesquisa/sul/7Parte2diagno sticoLagoass.pdf>.

SATO, J. Considerações Técnicas do Mapa da Vegetação do Brasil. Mata Atlântica: direito ambiental e a legislação. São Paulo, Ed. Hemus, p. 37, 1995.

SCCOTI, M. S. V.; ARAUJO, M. M.; WENDLER, C. F.; LONGHI, S. J. Mecanismos de regeneração natural em remanescente de floresta estacional decidual. Ciência florestal, v. 21, n. 3, p. 459-472, 2011. Disponível em: < http://dx.doi.org/10.5902/198050983803>. doi: 10.5902/198050983803

SCIPIONI, M. C.; GUIMARÃES, C. A.; CANTARELLI, E. B.; DENARDI, L.; MEYER, E. A. Fitossociologia em fragmento florestal no noroeste do estado do Rio Grande do Sul. Ciência Florestal, v. 21, n. 3, 2011. Disponível em: <http://dx.doi.org/10.5902/198050983799>. doi: 10.5902/198050983799

SILVA, A. F. DA; OLIVEIRA, R. V. DE; SANTOS, N. R. L.; PAULA, A. DE. Composição florística e grupos ecológicos das espécies de um trecho de floresta semidecídua submontana da fazenda São Geraldo, Viçosa - MG. Revista Árvore, v. 27, n.3, p.311-319, 2003. Disponível em: <http://dx.doi.org/10.1590/S010067622003000300006>. doi: 10.1590/S0100-67622003000300006

SILVEIRA, B. D. DA; FLORIANO, E. P.; NAKAJIMA, N. Y.; HOSOKAWA, R. T.; ROSOT, N. C.; GRACIOLI, C. R. Relação da morfometria e competição com o crescimento de Trichilia claussenii em um fragmento de floresta semidecidual, RS. 
Floresta, v. 45, n. 2, p. 373-382, 2015. Disponível em: <http://dx.doi.org/10.5380/rf.v45i2.3516>. doi: 10.5380/rf.v45i2.3516

SOS MATA ATLÂNTICA. Fundação SOS Mata Atlântica: flora, 2016. Disponível em: <http://www.sosmatatlantica.org.br/index.php?section=info\&action=flora $>$.

TABARELLI, M.; VENCESLAU A. A.; RIBEIRO M. C.; METZG, J.P. A Conversão da floresta atlântica em paisagens antrópicas: Lições para a conservação da diversidade biológica das florestas tropicais. Interciencia, v. 37, n. 2, p. 88-92, 2012. Disponível em: <http://dx.doi.org/0378-1844/12/02/088-05\$3.00/0>. doi: 0378$1844 / 12 / 02 / 088-05 \$ 3.00 / 0$

VENTUROLI, F.; CARVALHO, NETO, C. MELO de.; SILVA e.; MORAES, D. C.; MARTINS, T. O.; SOUZA, M. D. Manejo Florestal no bioma Cerrado: uma opção para conservar e lucrar. Scientia Forestalis, v .43, n. 107, p. 617-626, 2015. Disponível em <http://www.ipef.br/publicacoes/scientia/nr107/cap13.pdf>.

VIBRANS, A.C. How much remains of the Brazilian Atlantic forest in the state of Santa Catarina? Assessing the accuracy of forest cover maps using ground data from the Santa Catarina Forest and Floristic Inventory. Remote Sensing of Environment, Colombo, 2012. 